\title{
Mechano-Pharmacological Characterization of Cardiomyocytes Derived from Human Induced Pluripotent Stem Cells
}

\author{
Matthias Goßmann ${ }^{a, b}$ Ralf Frotscher ${ }^{c}$ Peter Linder ${ }^{b}$ Stephan Neumann ${ }^{b}$ \\ Robin Bayer $^{\mathrm{a}}$ Matthias Epple ${ }^{\mathrm{d}}$ Manfred Staat ${ }^{c}$ Ayșegül (Temiz) Artmann ${ }^{\mathrm{a}}$ \\ Gerhard M. Artmann ${ }^{b}$
}

Aachen University of Applied Sciences, Institute for Bioengineering (IfB), Laboratories of a Medical and Molecular Biology, bCell Biophysics, and 'Biomechanics, Jülich, Germany; University of Duisburg-Essen, Inorganic Chemistry and Center for Nanointegration Duisburg-Essen (CeNIDE), Germany

\section{Key Words}

Cardiac myocytes - Induced pluripotent stem cells • Heart tissue culture • CellDrum • Ion channels • Pharmacology $\bullet$ Inotropic compounds

\begin{abstract}
Background/Aims: Common systems for the quantification of cellular contraction rely on animal-based models, complex experimental setups or indirect approaches. The herein presented CellDrum technology for testing mechanical tension of cellular monolayers and thin tissue constructs has the potential to scale-up mechanical testing towards medium-throughput analyses. Using hiPS-Cardiac Myocytes (hiPS-CMs) it represents a new perspective of drug testing and brings us closer to personalized drug medication. Methods: In the present study, monolayers of self-beating hiPS-CMs were grown on ultra-thin circular silicone membranes and deflect under the weight of the culture medium. Rhythmic contractions of the hiPS-CMs induced variations of the membrane deflection. The recorded contraction-relaxation-cycles were analyzed with respect to their amplitudes, durations, time integrals and frequencies. Besides unstimulated force and tensile stress, we investigated the effects of agonists and antagonists acting on $\mathrm{Ca}^{2+}$ channels (S-Bay K8644/verapamil) and $\mathrm{Na}^{+}$channels (veratridine/ lidocaine). Results: The measured data and simulations for pharmacologically unstimulated contraction resembled findings in native human heart tissue, while the pharmacological doseresponse curves were highly accurate and consistent with reference data. Conclusion: We conclude that the combination of the CellDrum with hiPS-CMs offers a fast, facile and precise system for pharmacological, toxicological studies and offers new preclinical basic research potential.




\section{Cellular Physiology Cell Physiol Biochem 2016;38:1182-1198 \\ \begin{tabular}{l|l} 
and Biochemistry Published online: March 17, 2016 & $\begin{array}{l}\text { (c) } 2016 \text { The Author(s). Published by S. Karger AG, Basel } \\
\text { www.karger.com/cpb }\end{array}$
\end{tabular} \\ Goßmann et al.: Mechano-Pharmacological Characterization of hiPS-CMs}

\section{Introduction}

Considering the fact that the major function of the heart muscle is the generation of force and tensile stress, there is a remarkable lack of methods that can be routinely used for mechanical testing of cardiac myocytes in vitro. This shortcoming arises primarily from the fact that setups for mechanical force or stress measurements on that scale tend to be complex, poorly controllable and labor-intense. In particular, common mechanical measurements highly depend on the geometry of the test specimen and its connection to the measurement equipment. Thus, living samples of soft ultra-thin tissues are particularly difficult to characterize in comparison to other biogenic and non-biogenic materials. Previously developed mechanical techniques range from ex vivo methods, which make use of whole organs or partial explants to in vitro methods, commonly applied to isolated and/ or cultured cells.

The Langendorff heart [1] developed in the late $19^{\text {th }}$ century is still the most established technique to test cardio-active drugs [2]. It uses explanted mammalian hearts, kept in organ baths and perfused retrogradely with nutrient solutions containing cardio-active compounds. Despite its benefits in maintaining the structure of the organ, the Langendorff heart entails a list of significant drawbacks: Besides a huge demand for test animals and ethical concerns, the use of animal models itself may render the pharmacological results dubious due to their debatable translatability to human physiology. Additionally, the setup is fairly complex, making it unsuitable for high throughput analyses, which have become a rising and vital demand of the pharmaceutical industry.

Yet, the development of an adequate alternative has been an ongoing process for more than thirty years. In the meantime, various approaches for the quantification of cardiac contractility arose, each of which entailing assets and drawbacks regarding their accuracy, physiological relevance and scalability.

In 1986, Shepherd et al. mounted single bullfrog atrial myocytes to a pair of glass rods of known compliance [3]. The contractile force was calculated by means of optical displacement recording of the glass rods. Later, optical analysis was replaced by isometric force transduction $[4,5]$.

Harris et al. found that cells cultured on thin silicone substrates were able to produce wrinkles in the substrate [6]. They proposed to measure the magnitude of the cellular force by micromanipulation of the silicone sheets with microneedles of calibrated flexibility. A related concept uses elastic micropillars as a cell culture substrate [7]. Here, the deflection of each pillar is optically monitored. By calibrating the stiffness of the micropillars, the cellular force for each pillar can be calculated and summated.

All methods mentioned above have in common that a massive scale-up towards highthroughput analyses (e.g. for mid-stage preclinical studies) seems unfeasible. In analogy to manual patch-clamp experiments, their high accuracy and precision in the recorded data opposes the possibility to automatize and parallelize experiments.

In a different concept, Yin et al. used magnetic beads for measuring contractile forces of cardiac myocytes [8]. After attaching the beads to the cell, the displacement of the bead is optically recorded while a variable magnetic field is applied. Here, the cells are cultured on stiff substrates like glass or plastic in order to provide a stationary reference frame. The culture of cells on substrates of very high rigidity is suspected to significantly change mechanical characteristics $[9,10]$. The same restriction applies to atomic force measurements (AFM) [11] of cellular monolayers, where the stiff substrate is a fundamental prerequisite for accurate force transduction. Van Vliet et al. provide an extensive overview about the commonly used means for mechanical measurements of live tissue in vitro [12].

In 2010 Kevin Kit Parker et al. published a study on thin film biohybrids to measure contractile forces of cardiac myocytes. These biohybrids consist of a cantilever like thin flexible polymer layer and a monolayer of so-called cardiac engineered tissue. The cantilever acts like a bimetallic strip. Contraction of the cardiac myocytes results in a coiling of the construct, which is optically recorded and used to calculate the cellular stress $[13,14]$. As 


\section{Cellular Physiology Cell Physiol Biochem 2016;38:1182-1198

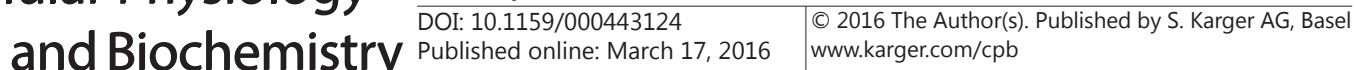 \\ Goßmann et al.: Mechano-Pharmacological Characterization of hiPS-CMs}

this system relies on uniaxial deformation of the construct, the orientation of the cells on the surface plays a crucial role. If the cells were allowed to settle with random orientation on the substrate, only a portion of the exerted force would contribute to deformation. In view of this issue, surface micro structuring was applied to enforce alignment of the cells in the desired direction [15]. In this way, the natural alignment in the native heart tissue is modeled as a highly desirable byproduct. In additional studies, the optimal aspect ratio for maximal force transduction was examined [16].

In a different concept, Eschenhagen et al. developed so-called engineered heart tissues to examine contractile forces. These are ring-shaped gels formed from extracellular matrix proteins and seeded with cardiac myocytes. The rings are placed around two flexible polymer posts, which are deflected due to cellular forces. The deformation is analyzed indirectly by video observation or directly via a force transducer $[17,18]$. In subsequent studies the rings were replaced with dumbbell-shaped constructs between the posts [19]. For contractile property determination of human embryonic stem cell-derived cardiomyocytes (hESC$\mathrm{CMs}$ ) another method was used. Autonomously beating hESC-CMs clusters were co-cultured in irreversibly ischemically damaged slices of neonatal murine ventricles. After cluster integration isometric force measurements were performed. The cavity of the left ventricle provided a preformed hole allowing tissue mounting onto the tips of two adjacent steel needles. The hESC-containing spontaneously beating rings were mounted on an isometric force transducer and the length was increased stepwise until the maximal force development was reached [20].

Besides force measurements, other approaches make use of indirect methods to quantify cellular mechanics. One common application uses fluorescent dyes to quantify $\mathrm{Ca}^{2+}$ concentrations in the cytoplasm as an indicator for contractility [21]. As this approach relies on optical components, which could be miniaturized in the past decades by orders of magnitude by digital technologies, it enables real high-throughput analyses with up to 1536 samples at a time. This renders indirect contractility measurements available for preclinical trials for the first time. The major drawback of this technology is its underlying assumption of a direct correlation between the concentration of cytoplasmic $\mathrm{Ca}^{2+}$ and the contractility of a myocyte. A known issue of this approach is the interruption of the excitation-contraction coupling [22]. While those interruptions may have pathologic reasons, recently developed cardio-active drugs like the $\mathrm{Ca}^{2+}$-sensitizer levosimendan [23], a cardiac myosin activator called omecamtiv mecarbil [24] and the myosin II ATPase antagonist blebbistatin [25] even make use of this effect.

Finally, electric cell-substrate impedance sensing is used to evaluate the shape of cells cultured on gold electrodes. First described in 1986 [26], it was used for measuring kinetics of cell spreading [27] and cytotoxicity [28]. In recent years, advances in data transfer rates allowed the measurement of cardiac beating with a high resolution. Like $\mathrm{Ca}^{2+}$ measurements, this system provides indirect information about the contractile forces, implying a direct relationship between force or tension and shape.

In the present study we intended to overcome previous technological drawbacks by using the CellDrum technology [29-33] to characterize cardiac myocytes, derived from human induced pluripotent stem cells (hiPS cells), with respect to their response to wellcharacterized positively and negatively acting inotropes. Previously, this technology has been applied to neonatal rat cardiac myocytes [31] and endothelial cells [32].

The key factor of the CellDrum technology is a well-defined biomechanical environment for cells, combined with a high degree of experimental handling simplicity. The cells are cultured on a physically defined reference material consisting of an ultra-thin silicone membrane sealing the bottom of a cell culture well. In the present design, the well has a diameter of $16 \mathrm{~mm}$ which corresponds to a standard 24-well-plate. While being deflected by the weight of the culture medium, a rhythmic contraction of the auto-contractile cardiomyocytes lifts the membrane upwards.

The deflection is monitored by a laser triangulation sensor. Simultaneously, the pressure beneath the membrane is recorded. The tension of the membrane is calculated from the 


\section{Cellular Physiology Cell Physiol Biochem 2016;38:1182-1198 \begin{tabular}{c|c|c|} 
DOI: 10.1159/000443124 & and Biochemistry \\
Published online: March 17, 2016 & $\begin{array}{l}\text { O 2016 The Author(s). Published by S. Karger AG, Basel } \\
\text { www.karger.com/cpb }\end{array}$ \\
\cline { 2 - 3 }
\end{tabular} \\ Goßmann et al.: Mechano-Pharmacological Characterization of hiPS-CMs}

recorded values by application of Laplace's law. The utilization of self-beating hiPS-derived cardiac myocytes promises to avoid present-day issues regarding cross-species translation and ethical concerns while enabling the production of an essentially infinite amount of human material for examination.

We have investigated the effects of inotropes acting on $\mathrm{Ca}^{2+}$ channels (S-Bay K8644/ verapamil) and $\mathrm{Na}^{+}$channels (veratridine/lidocaine) in commercially available hiPS-derived cardiomyocytes. The inotropes were selected for their action on the contractility of heart tissue rather than their common clinical application.

In particular, we intended to examine the contraction-relaxation-cycles (CR-cycles) regarding their morphology changes upon drug application. Beyond their amplitude, we examined the durations of the CR-cycles as well as their time integral as an additional potential measure for inotropy. Finally, the beating frequency was monitored.

\section{Materials and Methods}

\section{CellDrum Technology}

Key factors of the CellDrum technology [29-35] (Fig. 1) are a well-defined, approximately isotropic and homogeneous biomechanical cell tension environment, combined with a good degree of experimental handling simplicity. The cells are cultured on a soft, $3 \mu \mathrm{m}$ thin silicone membrane sealing the bottom of a plastic cylinder. This set-up, membrane and cylinder, resembles one CellDrum (Fig. 1). Each individual CellDrum (well) has a diameter of $16 \mathrm{~mm}$ and a height of $10 \mathrm{~mm}$. It is placed in a Single Well Tissue Tension Analyzer. Due to the weight of the cell culture medium the membrane deflects downwards. The inner side of the membrane is covered with a monolayer of hiPS derived cardiac myocytes (Cor.4U, Axiogenesis AG, Köln). Mechanical rhythmic cell contraction and relaxation of the auto-contractile cardiomyocytes lifts the membrane up and down, respectively. The deflection is monitored by a laser triangulation sensor (model LK-G31, KEYENCE Deutschland GmbH, Neu-Isenburg, Germany). Simultaneously, the pressure beneath the membrane is recorded by a pressure sensor (model AP47, KEYENCE Deutschland GmbH, Neu-Isenburg, Germany). The tension of the membrane is calculated from the deflection by applying Laplace's law [36].

\section{CellDrum membrane manufacturing}

Membranes were manufactured at the IfB laboratories using poly(dimethylsiloxane) (PDMS, Sylgard 184, Dow Corning, Midland, MI, USA). The inner CellDrum surface was chemically functionalized to achieve long-term cardiac myocyte attachment. CellDrums were manually produced and tested for

Fig. 1. Schematic drawing of single CellDrum Tissue Tension Analyzer: 1) cylindrical CellDrum culture medium container, 2) ring heater, 3) air pump, 4) laser triangulation sensor 5) culture medium, 6) membrane and cell monolayer, each $3 \mu \mathrm{m}$ thick, 7) Insert: CellDrum, enlarged: cell monolayer.

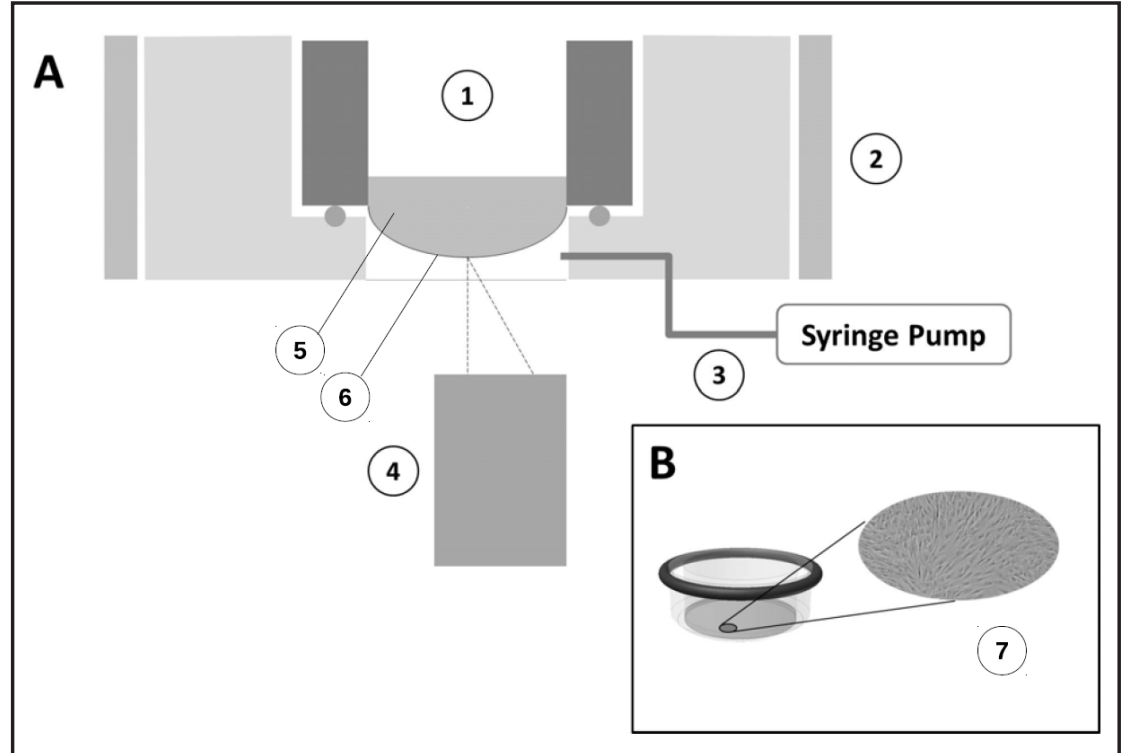




\section{Cellular Physiology Cell Physiol Biochem 2016;38:1182-1198 \begin{tabular}{l|l} 
and Biochemistry POI: 10.1159/000443124 & $\begin{array}{l}\text { D) 2016 The Author(s). Published by S. Karger AG, Basel } \\
\text { www.karger.com/cpb }\end{array}$
\end{tabular} \\ Goßmann et al.: Mechano-Pharmacological Characterization of hiPS-CMs}

constant thickness by thin-film interferometry. Membranes of $3.0 \pm 0.3 \mu \mathrm{m}$ thicknesses were selected for pharmacological experiments.

\section{Buffers}

Ingredients were purchased from: 1) Phosphate buffered saline (PBS) and trypsin/ ethylenediaminetetraacetic acid (EDTA) (Life Technologies, Karlsruhe, Germany); 2) Isopropyl-alcohol and hydrochloric acid (37\%) (Carl Roth, Karlsruhe, Germany), and 3) 2-(N-morpholino)ethanesulfonic acid (MES) (USB Corporation, Cleveland, OH, USA).

\section{Membrane functionalization}

"Classical" fibronectin deposition as usually used [32] was not sufficient to enable long-term adhesion of hiPS-derived cardiac myocytes. Thus, a three-step functionalization protocol consisting of a wet-chemical oxidation step [37], epoxy-silane conjugation from alcohol solution [38] and covalent binding of fibronectin was adopted [39].

For membrane oxidation, the CellDrum membranes were exposed to $500 \mu \mathrm{L}$ oxidation solution for $30 \mathrm{~min}$ at room temperature. The oxidation solution consisted of a mixture of $\mathrm{H}_{2} \mathrm{O} / \mathrm{H}_{2} \mathrm{O}_{2}(20 \%) / \mathrm{HCl}(37 \%)$ (5:1:1 volume ratio) and was prepared immediately before application. For silane deposition isopropyl alcohol and water were mixed at a volume ratio of 95/5 and adjusted to pH 5.0 with acetic acid. For fibronectin coating, a $50 \mathrm{mM}$ MES buffer was prepared, adjusted to $\mathrm{pH} 6.1$ with $1 \mathrm{M} \mathrm{NaOH}$, and sterilized with a $0.22 \mu \mathrm{m}$ filter. After thorough washing with deionized water, $200 \mu \mathrm{L}$ of a $2 \%$ solution of trimethoxy[2(7-oxabicyclo[4.1.0]hept-3-yl)ethyl]silane (3MOBS) in silane deposition solution were added and left to incubate for $5 \mathrm{~min}$. After another washing step, the freshly prepared silane layer was cured by autoclaving $\left(121^{\circ} \mathrm{C}, 0.2 \mathrm{MPa}, 20 \mathrm{~min}\right)$. Finally, fibronectin from bovine blood plasma was diluted to a final concentration of $10 \mu \mathrm{g} \mathrm{mL} \mathrm{m}^{-1}$ with MES coating buffer. Each CellDrum membrane was incubated with $500 \mu \mathrm{L}$ of this solution overnight. The solution was removed shortly before seeding the cells. Functionalization did not affect the mechanical properties of the membranes significantly (data not shown).

\section{Cell Culturing}

Autonomously beating human hiPS-derived cardiac myocytes were chosen for experiments avoiding present-day discussions regarding cross-species translation as well as ethical concerns. Cells originate from human skin fibroblasts reprogrammed by the application of the Yamanaka factors [40]. They were terminally differentiated to cardiac myocytes and selected using the $\alpha \mathrm{MHC}$ promotor driving a puromycin resistance gene. Electrophysiological analyses indicate that these cardiac myocytes are a pan-organ population of ventricular, atrial, and nodal cells [41]. According to manufacturer data, cells consist of approximately $60 \%$ ventricular, $35 \%$ atrial, and 5\% nodal cells. Cells were delivered live in standard cell culture flasks. After trypsinization, they were seeded on CellDrum membranes at a density of 150,000 cells $\mathrm{cm}^{-2}$ (a representative figure in [42] shows the irregular assembly of the cells in the confluent monolayer on a CellDrum membrane). The culture medium was replaced every day. Within 6 to 8 days of culture, cell synchronization occurred spontaneously in all CellDrums. Experiments were carried out after seven more days of culture.

\section{Pharmacological agents}

In these experiments S-Bay K8644 a selective calcium channel opener was used at concentrations up to $150 \mathrm{nM}$. As antagonist the selective calcium channel blocker verapamil up to $300 \mathrm{nM}$ was chosen. As potassium channel modulators veratridin up to $2500 \mathrm{nM}$ was applied as agonist, and lidocaine up to $2500 \mathrm{nM}$ as potassium channel antagonist. Agents were purchased from Sigma Aldrich.

The optimal concentration range for each drug was estimated in preliminary experiments.

\section{Cell Monolayer Mechanical Tension Determination}

Under the pressure $p$ the CellDrum membrane deflects in a spherical cap of a ball with radius (of curvature) $R$. The tensile stress of the membrane is calculated using Laplace's formula for a spherical thinwalled pressure vessel with thickness $t$ :

$$
\sigma=\frac{p \cdot R}{2 \cdot t}
$$

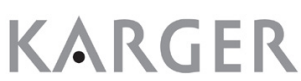




\section{Cellular Physiology Cell Physiol Biochem 2016;38:1182-1198 \begin{tabular}{l|l} 
and Biochemistry Published online: March 17, 2016 & $\begin{array}{l}\text { C) 2016 The Author(s). Published by S. Karger AG, Basel } \\
\text { www.karger.com/cpb }\end{array}$ \\
\hline
\end{tabular} \\ Goßmann et al.: Mechano-Pharmacological Characterization of hiPS-CMs}

The radius $R$ can be obtained from the deflection $h$ by the Pythagorean Theorem:

$$
R^{2}=(R-h)^{2}+r^{2}
$$

where $r$ is the radius of the CellDrum ( $r=8 \mathrm{~mm}$ ). This can be solved for:

$$
R=\frac{r^{2}}{2 \cdot h} \cdot\left(1+\frac{h^{2}}{r^{2}}\right)
$$

After combining equations (1) and (3), the outcome is the general dependency between the stress $\sigma$, the differential pressure $p$, the resulting deflection $h$ of the membrane, and the dimensions of the CellDrum:

$$
\sigma=\frac{p}{h} \cdot \frac{r^{2}}{4 \cdot t} \cdot\left(1+\frac{h^{2}}{r^{2}}\right)
$$

For cell tension measurement, the CellDrums were integrated into a temperature-controlled measurement chamber and equilibrated for $500 \mathrm{~s}$. After this period, the strains of the membranes were adjusted to $0.3-0.5 \%$ by application of air pressure. Subsequently, the cells were incubated with six increasing concentrations of the respective cardio-active compound for $5 \mathrm{~min}$, starting with the control (no compound). The compounds were added cumulatively by replacing $20 \%$ of the culture medium containing the necessary amount to achieve the desired concentration. In order to exclude compound-independent effects like temperature, media $\mathrm{pH}$ or mechanical influences during media exchange, baseline measurements without compounds were recorded as stated above. Compound effects were normalized to controls.

\section{Data Analysis}

Data were recorded at a sample rate of $1 \mathrm{kHz}$ (LabView 2010, National Instruments, Austin, Texas, USA). For each data point, 10 contraction-relaxation-cycles (CR-cycles) were matched and filtered with a moving averaging data filter over one hundred beats. Individual beats were analyzed for: a) contraction amplitude and $b$ ) beat duration, c) the contraction vs. time curve integral (area between curve and baseline). In addition, the beating frequency was analyzed (Fig. 2).

\section{Mathematical Modeling and Computer Simulations}

With this part of the paper the intention was to outline that computer simulations may very well complement the experimental data shown here. Detailed cell physiological models have been programmed for atrial, sinoatrial and ventricular cells. Each of these Hodgkin-Huxley type models consists of ordinary differential equations describing the kinetics of up to 20 ion channel gates, of sodium, calcium and potassium ions and of the membrane potential of an individual cell. In sum, the resulting individual ion channel currents give the total electrical current across the membrane.

The macroscopic electromechanically coupled model has been implemented and the simulations have been performed in the open source Finite Element software Code_Aster provided by the French electric utility company EDF (Électricité de France SA, Paris, France). Details including basic equations and additional simulations are presented in [42-44]. Parameter fittings and other statistical assessments related

Fig. 2. Parameters of an individual cell contractionrelaxation-cycle: a) Contraction amplitude, b) duration of the contraction-relaxation-cycle, c) time-integral of the contraction-relaxation-cycle.

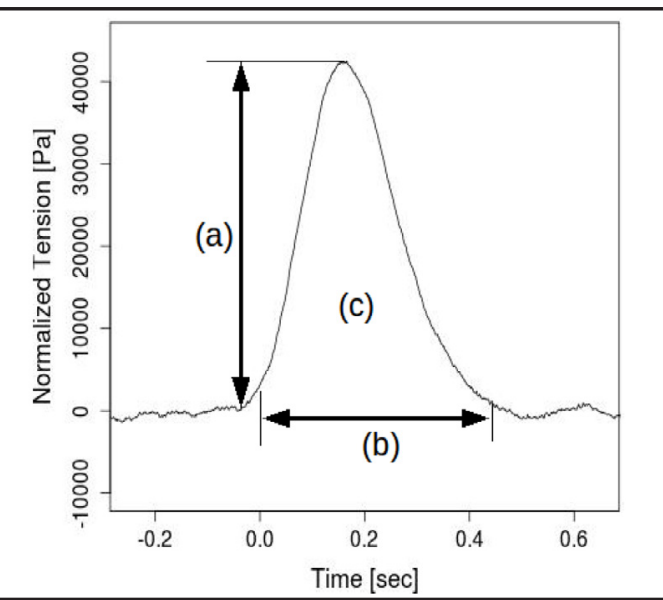




\section{Cellular Physiology Cell Physiol Biochem 2016;38:1182-1198 \begin{tabular}{l|l|l} 
DOI: 10.1159/000443124 & O 2016 The Author(s). Published by S. Karger AG, Basel \\
www.karger.com/cpb
\end{tabular} \\ Goßmann et al.: Mechano-Pharmacological Characterization of hiPS-CMs}

to the simulations have been performed in the statistics software $\mathrm{R}$ and in Scilab. Due to the fine time and spatial resolutions we employed eight processors and provide up to eight GB memory on a Dell Precision workstation containing 16 CPUs and 32 GB memory.

Statistics

Each experiment was repeated 4 to 6 times. Values are given as mean values \pm 1 standard deviation. Mann-Whitney U test was performed using the statistical software platform GNU R.

\section{Results}

\section{Unstimulated Contractile Force and Stress}

Table 1 summarizes the mechanical properties found in the literature. The results of the present study are listed in the last row. Contraction forces measured with the various setups range from 0.01 to $40 \mu \mathrm{N}$ for single cells and from 110 to $340 \mu \mathrm{N}$ for three-dimensional constructs, while the stresses range between 5.3 and $51 \mathrm{kPa}$.

\section{Inotropic Drugs}

Four different cardio-active drugs which target $\mathrm{Ca}^{2+}$ channels (S-Bay K8644/verapamil) and $\mathrm{Na}^{+}$channels (veratridine/lidocaine) were applied to hiPS-derived cardiac myocytes.

Table 1. Contractile force and tensile stress of cardiomyocytes reported in the literature, compared with the results of this study (last row) * IFT=isometric force transduction, AFM=atomic force microscopy, EM=elastic micropillars, $\mathrm{CD}=$ CellDrum, MTF $=$ Muscular Thin Film, ${ }^{* *}$ depending on substrate elasticity, ${ }^{* * *}$ equibiaxial

\begin{tabular}{llllllll}
\hline Species & Tissue & Maturity & Preparation & Setup* & Force $[\mu N]$ & Stress [kPa] & Source \\
\hline Frog & Atrial & adult & single cell & Optical & 0.2 & $-/-$ & {$[3]$} \\
Guinea pig & Ventricular & adult & single cell & Optical & $1.23 \pm 0.44$ & $5.3 \pm 2.6$ & {$[45]$} \\
Mouse & pan-organ & iPS & cell cluster & IFT & 2.7 & $-/-$ & {$[5]$} \\
Rat & $-/-$ & newborn & single cell & IFT & $20-40$ & 9.05 & {$[46]$} \\
Rat & Ventricular & adult & single cell & IFT & $-/-$ & 41.1 & {$[47]$} \\
Rat & Ventricular & adult & single cell & IFT & $-/-$ & $17.7 \pm 1.7$ & {$[48]$} \\
Rat & Ventricular & embryonic & single cell & AFM & 0.012 & $-/-$ & {$[11]$} \\
Rat & $-/-$ & embryonic & single cell & EM & $0.01-0.8 * *$ & $-/-$ & {$[7]$} \\
Rat & Ventricular & newborn & 3D matrix & IFT & $340 \pm 30$ & $-/-$ & {$[49]$} \\
Rat & Ventricular & newborn & 3D matrix & Optical & $110-220$ & $-/-$ & {$[19]$} \\
Rat & Ventricular & newborn & Monolayer & MTF & $-/-$ & $15.4 \pm 1.4$ & {$[14]$} \\
Rat & Ventricular & newborn & Monolayer & MTF & $-/-$ & $9.2 \pm 3.5$ & {$[13]$} \\
Rat & Ventricular & newborn & Monolayer & MTF & $-/-$ & $20.7 \pm 5.6$ & {$[50]$} \\
Human & Ventricular & adult & single cell & IFT & $-/-$ & $51 \pm 8$ & {$[51]$} \\
Human & Ventricular & adult & single cell & IFT & $-/-$ & $29.6 \pm 4.5$ & {$[4]$} \\
Human & pan-organ & iPS & Monolayer & CD & $-/-$ & $43.1 \pm 7.5^{* * *}$ & this work \\
\hline
\end{tabular}

Table 2. Overview on global inotropic and chronotropic effects on hiPS-derived cardiomyocytes

\begin{tabular}{lllll} 
& S-Bay K8644 & Verapamil & Veratridine & Lidocaine \\
\hline Amplitude & $\uparrow$ & $\downarrow$ & $\uparrow$ & $\downarrow$ \\
Integral & $\uparrow$ & $\downarrow$ & $\uparrow$ & $\downarrow$ \\
Duration & $\uparrow$ & $\rightarrow$ & $\rightarrow$ & $\rightarrow$ \\
Frequency & $\downarrow$ & $\uparrow$ & $\downarrow$ & $\downarrow$ \\
\hline
\end{tabular}


Fig. 3. Representative recordings of the dosedependent effects of SBay K8644 (upper panel) and verapamil (lower panel) on the contractility of hiPS-derived cardiomyocytes.
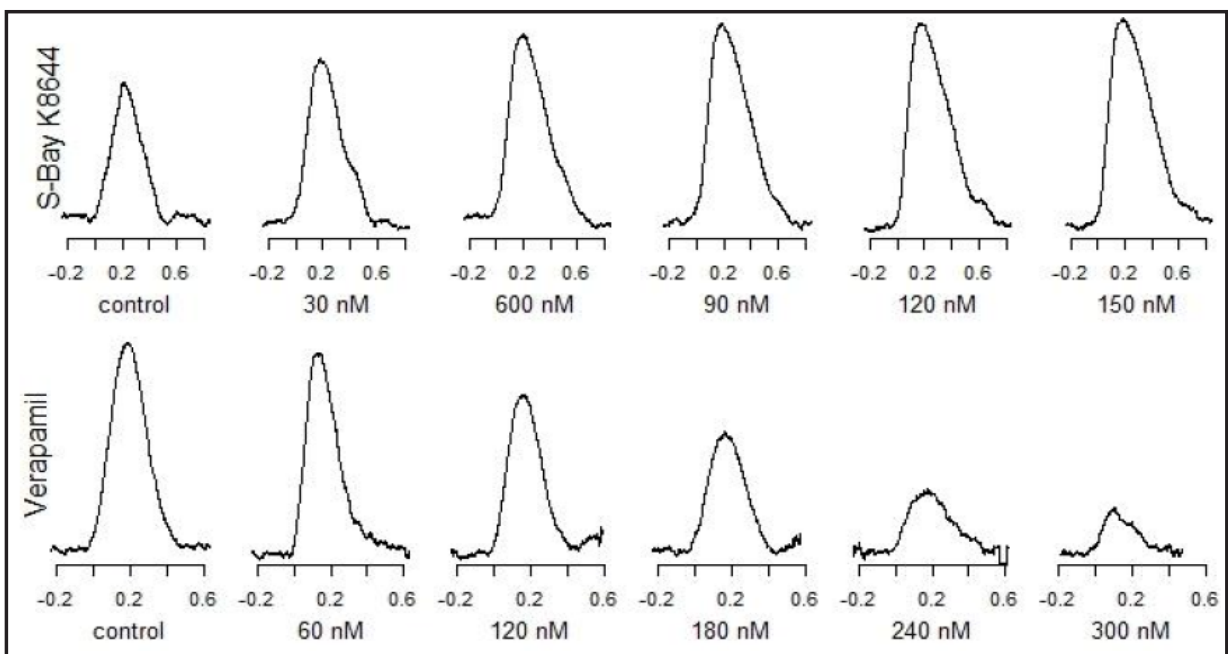

Fig. 4. Effect of calcium channel modulators S-Bay K8644 (left) and verapamil (right) on the amplitude, time-integral, duration and frequency of the contraction-relaxation-cycles of hiPS-derived cardiomyocytes. $* p<0.05$.

Table 2 summarizes the effects of the compounds on the amplitude, time integral, duration and frequency of the recorded CR-cycles which are explained in Fig. 2.

\section{$\mathrm{Ca}^{2+}$ Channel Modulators}

Representative recordings of the $\mathrm{Ca}^{2+}$ channel agonist S-Bay K8644 and antagonist verapamil are shown in Fig. 3. S-Bay K8644 (Fig. 4 left) raised the amplitude of the CR-cycle to $160 \%$ up to a concentration of $90 \mathrm{nM}$. The same applied for the duration. Above $90 \mathrm{nM}$, both values were not changed significantly. As result from the increase in amplitude and duration, the time integral was raised to $250 \%$ at $90 \mathrm{nM}$. Concurrently, the beating frequency was reduced above $60 \mathrm{nM}$ to $80 \%$ at $150 \mathrm{nM}$.

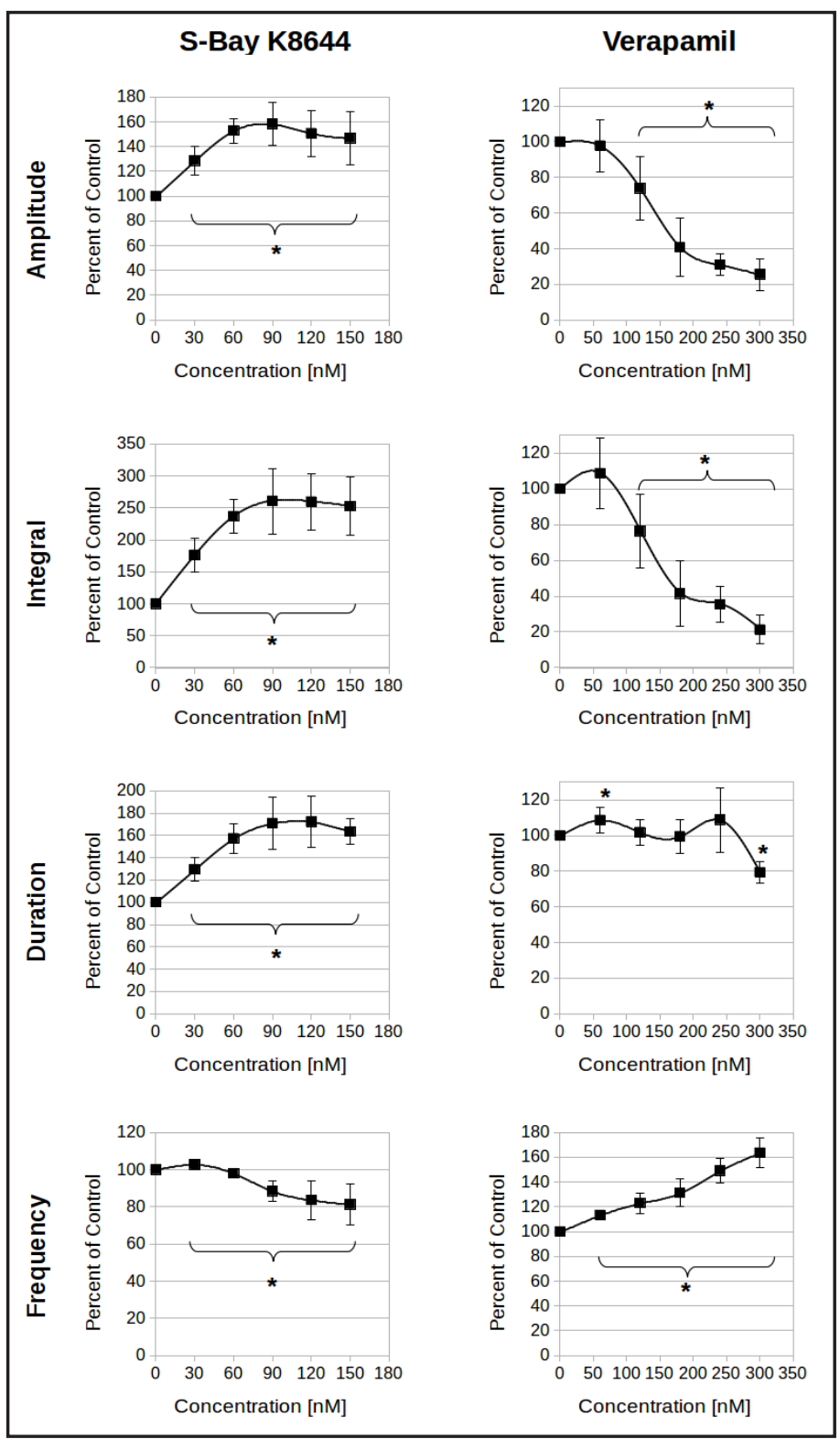

\section{KARGER}


Fig. 5. Effect of sodium channel modulators veratridine (left) and lidocaine (right) on the amplitude, time-integral, duration and frequency of the contraction-relaxation-cycles of hiPS-derived cardiomyocytes. * $p<0.05$.

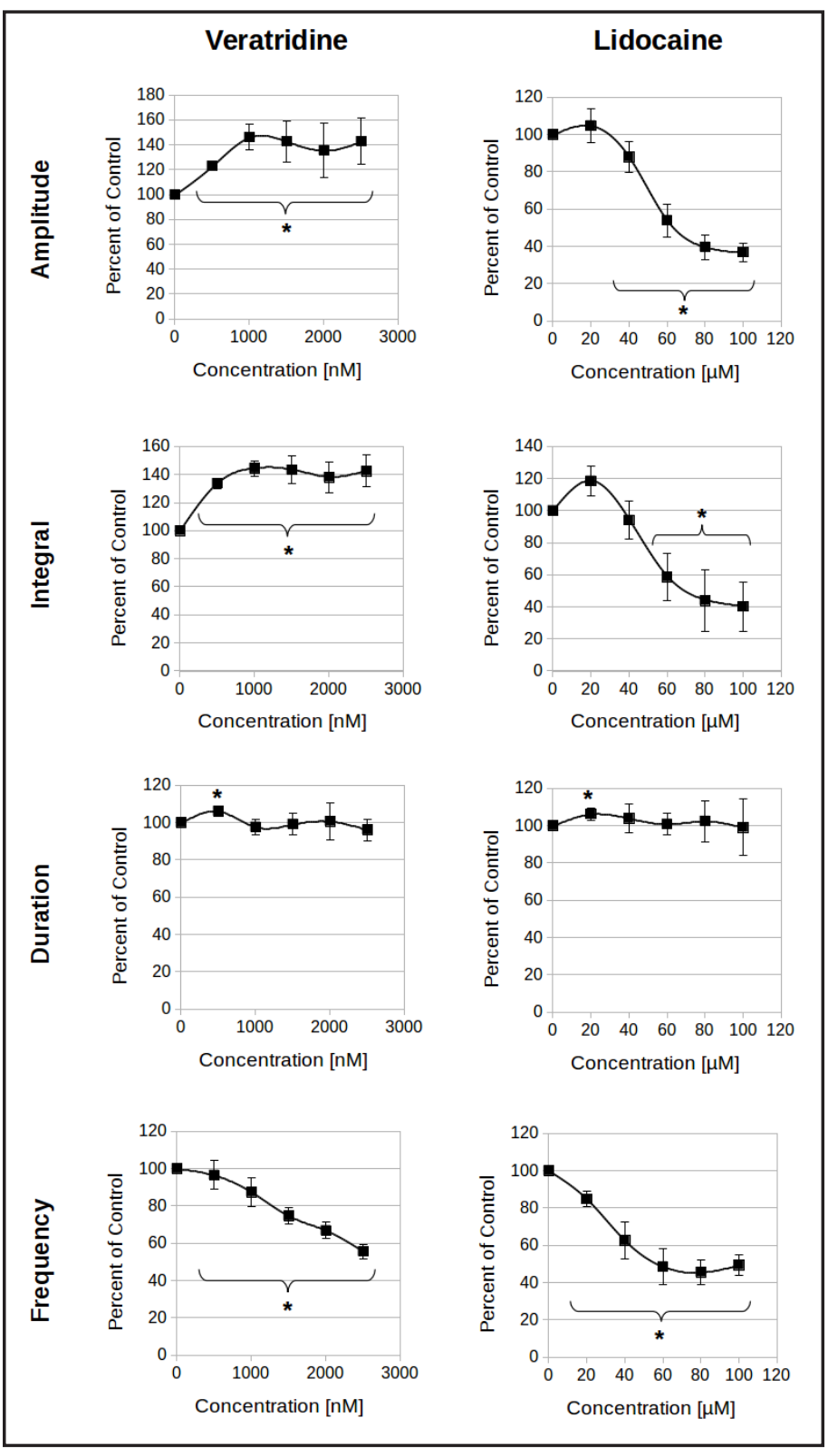

It reduced the amplitude to $25 \%$ at $300 \mathrm{nM}$ (Fig. 4 right). While the duration was only decreased at the highest concentration of $300 \mathrm{nM}$, the time integral was reduced in accordance to the amplitude to $20 \%$ at the highest dose. The frequency was increased in a linear manner to $160 \%$ at $300 \mathrm{nM}$ and did not reach saturation.

\section{$\mathrm{Na}^{+}$Channel Modulators}

The $\mathrm{Na}^{+}$channel agonist veratridine (Fig. 5 left) increased both the amplitude and time integral to $140 \%$ at a concentration of $1 \mu \mathrm{M}$, while the duration was not changed up to $2.5 \mu \mathrm{M}$. The frequency was reduced to $60 \%$ in a linear dose-dependent manner. Above this concentration, the compound induced pro-arrhythmic events (Fig. 6) and finally massive fibrillations.

The $\mathrm{Na}^{+}$channel antagonist lidocaine (Fig. 5 right) reduced the amplitude to $40 \%$ at $100 \mu \mathrm{M}$. Beyond this concentration, rhythmic contraction ceased. The duration of the CRcycle was unchanged. As a result, the time integral was decreased in accordance with the amplitude to $40 \%$ at the highest dose. The frequency was decreased to $50 \%$ at $60 \mathrm{nM}$. 


\section{Computer Simulations}

The herein and in other papers [31, 34] presented experimental results provide a fundamental basis for the validation and parameterization of the computational model previously presented in [42] where theoretical details and the simulation results in Fig. 7 and Fig. 8, respectively can be found. The electromechanically coupled finite element model is mainly based on electrophysiological measurements published in the literature. Within the model it is possible to modify the microscopic cellular models that represent the cellular electrophysiology via systems of ordinary differential equations, in terms of drug application. Inotropic and chronotropic effects of the calcium channel modulators S-Bay K8644 and verapamil as well as of the sodium channel modulators veratridine and lidocaine have been simulated in [43]. Therein the different modes of action of a drug and the sensitivity of the ion channels with respect to that drug are taken into account. In [44] the authors describe a suitable way how to modify the cellular conductivity in the employed models of cellular electrophysiology in order to match the phenomenologically observed beating frequencies.

Figure 7 shows experimentally determined vs. simulated inotropic effects (relative membrane deflection) of lidocaine. The normalized curve in Fig. 7 shows a good qualitative agreement between experiment and simulation in terms of the inotropic effect of lidocaine although there is a quantitative disagreement that is hidden by the normalization but is thoroughly discussed in [42]. Nevertheless, even the seemingly nonlinear relationship between lidocaine concentration and membrane deflection in the range of 0 to $100 \mu \mathrm{M}$ can be captured quite well.

Figure 8 represents the mean experimental results which have been obtained with two different cell cultures exposed to S-Bay K8644. The computational model could be adapted to the respective, phenomenologically observed beating frequency, keeping the ability to simulate the drug effect. With the experiment-specific modifications of the conductance $g_{K 1}$ of the inward-directed rectifier potassium current

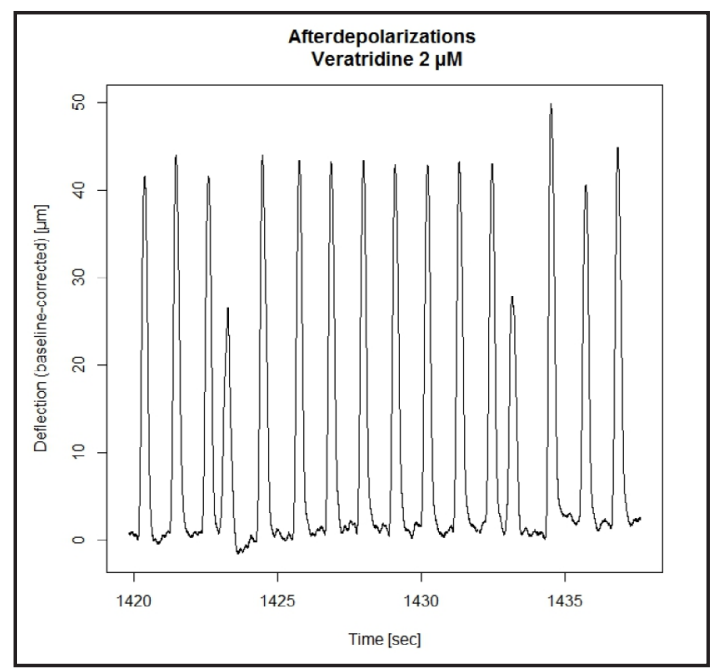

Fig. 6. Pro-arrhythmic events (early afterdepolarizations) for $2 \mu \mathrm{M}$ veratridine.

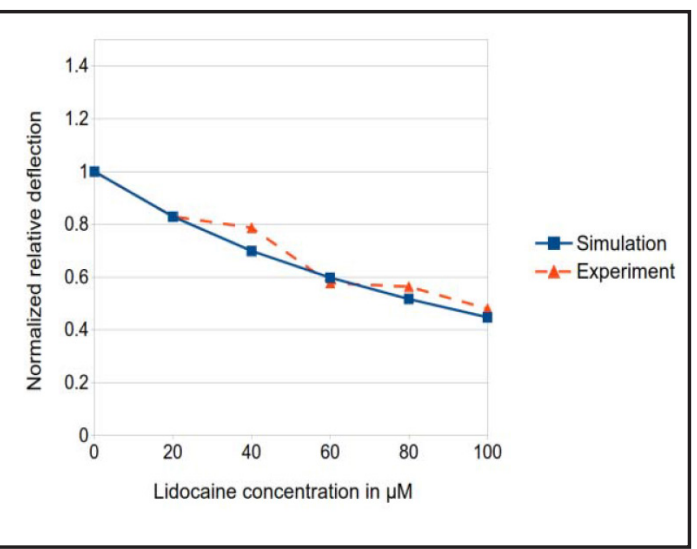

Fig. 7. Experimentally determined vs. simulated inotropic effects (relative membrane deflection) of lidocaine.

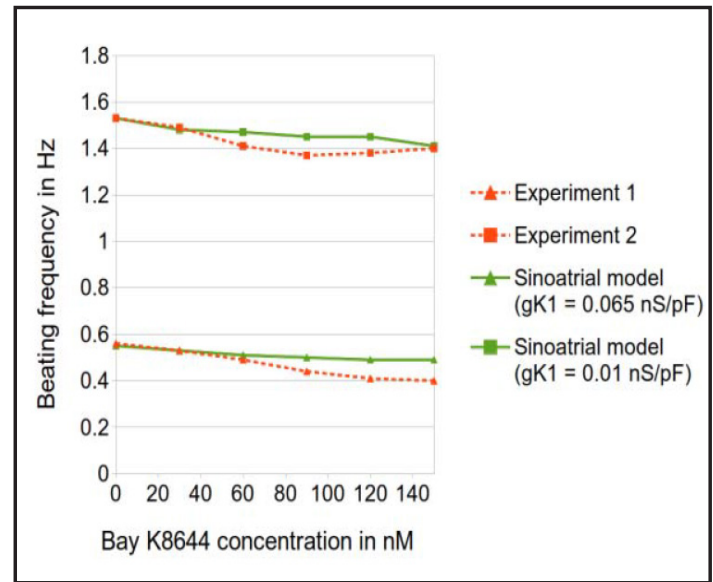

Fig. 8. Experimentally vs. simulated beating frequencies using S-Bay K8644 for two cell cultures. 


\section{Cellular Physiology Cell Physiol Biochem 2016;38:1182-1198 \\ \begin{tabular}{c|c|c|} 
DOI: 10.1159/000443124 & O 2016 The Author(s). Published by S. Karger AG, Basel \\
www.karger.com/cpb
\end{tabular} \\ Goßmann et al.: Mechano-Pharmacological Characterization of hiPS-CMs}

in the cellular model we were able to capture the beating frequency of the monolayer under control conditions while keeping the ability to appropriately simulate the drug effect. Results like these indicate that the computational model is able to support the interpretation of experimental results by means of simulating hypotheses concerning differently expressed ion channels in different cell cultures.

From these two examples it can be concluded that even in this preliminary modeling the comparison between experimental and simulated data, respectively, are surprisingly good. Further computational results, including the chronotropic effect of lidocaine and the inotropic effect of S-Bay K8644 can be found in [42-44].

\section{Discussion}

Unstimulated Contractile Force and Stress

Literature data (Table 1) show broad ranges of cell layer force and tensile stress, respectively. Even the data based on the most commonly used and established isometric force transduction setup vary greatly. Possible (biological) reasons might result from donor varieties or the developmental stage of the tissue. Furthermore, force itself does not intrinsically contain any information about the geometry of the test specimen, making results incomparable. The deviations of the geometrically normalized stress values are substantially smaller (Table 1). Hence, it seems reasonable to restrict the comparison of our findings to only the stress data. In this context we conclude that the results from this study with hiPS-derived cardiac myocytes ( $43.1 \pm 7.5 \mathrm{kPa}$ unstimulated stress amplitude) compare well to the findings of van der Velden et al. with adult human cardiac myocytes from healthy biopsy material $[4,51]$.

\section{Computer simulation}

The developed software and contemporary hardware availability allows simulations of the contractile behavior of the cell layer and estimation of drug effects (Fig. 7 and Fig. 8). The comparison of experimental results with simulation results revealed that a phenomenological adjustment in the absence of drugs could lead to a quantitatively quite good agreement between experiment and simulation [43]. Our qualitative simulations of drug action (Fig. 7) indicate necessary model improvements to quantitatively capture the beating force of the cell layer. Promising mechanisms to adopt the beating frequency of the models to the experimentally determined ones have been selected and are under current investigation. The ability to adjust the models to certain beating frequencies while keeping the potential to model drug action can be seen in Fig. 8. It can be concluded that the CellDrum experiments enroll the capability to test the ability of computational models to simulate both, chronotropic and inotropic drug action on cardiac monolayers and (in the future) also 3D tissue.

\section{$\mathrm{Ca}^{2+}$ Channel Modulators}

The influence of S-Bay K8644 on the contractility of cardiac myocytes is consistent with its effect on their action potential [52]. Through the increase of $\mathrm{Ca}^{2+}$ influx, the transient $\mathrm{Ca}^{2+}$ concentration in the cell is raised, followed by an increased Calcium-Induced Calcium Release from the sarcoplasmic reticulum [53].

The prolonged activation of $\mathrm{Ca}^{2+}$ channels is the reason of increased influx of positive ions into the cell. This corresponds to the prolongation of the CR-cycle. In respect to the contraction amplitude, the effect of S-Bay K8644 measured with the CellDrum technology is in accordance with atrial preparations [52] and ventricular slices [54] of the guinea pig as well as with the results obtained with preparations from pig coronary artery [55].

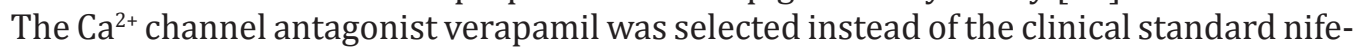
dipine due to its selective action on the heart tissue instead of the vascular system $[56,57]$. In contrast to S-Bay K8644, it does not modify the duration of the CR-cycle. This confirms the findings of Singh et al. that verapamil does not modify the duration of the ventricular action potential [58]. However, this is only correct at the concentrations investigated here. 


\section{Cellular Physiology Cell Physiol Biochem 2016;38:1182-1198 \\ \begin{tabular}{c|c|c|} 
DOI: 10.1159/000443124 & O 2016 The Author(s). Published by S. Karger AG, Basel \\
www.karger.com/cpb
\end{tabular} \\ Goßmann et al.: Mechano-Pharmacological Characterization of hiPS-CMs}

Verapamil is known to inhibit both Ca and hERG channels at higher concentrations. The time integral and amplitude both respond to increasing concentrations of the drug.

The $\mathrm{IC}_{50}$ value of approximately $150 \mathrm{nM}$ for the contraction amplitude measured in this study was comparable to the findings of Singh et al. [58] (300 nM) and an order of magnitude lower than literature data obtained with papillary muscle preparations of rabbit [59], cat [60] and dog [61].

In the current study, both compounds had an inverse effect on the beating frequency as compared to native heart tissue. This effect was reported for $\mathrm{Ca}^{2+}$ channel modulators on hiPS-derived cardiomyocytes in electrophysiological studies, where different hiPS-derived cell lines displayed different responses to those agents but their pharmacology was different from that observed in primary human heart cells $[62,63]$.

\section{$\mathrm{Na}^{+}$Channel Modulators}

Like verapamil, veratridine and lidocaine have no effect on the duration of the CRcycle. As a result, their amplitudes and time integrals increase/decrease concurrently. Veratridine induced proarrhythmic events at concentrations above $2.5 \mu \mathrm{M}$. For lidocaine the concentrations could be increased up to $100 \mu \mathrm{M}$ until the cells stopped beating. In accordance with literature data, application of lidocaine did not result in an increase of frequency but rather in a decrease $[64,65]$.

In respect to the contraction amplitude, the $\mathrm{EC}_{50}$ value of approximately $700 \mathrm{nM}$ was slightly higher than reported in the literature (400 nM) [66]. In contrast, the $\mathrm{IC}_{50}$ value of veratridine $(1.5 \mu \mathrm{M})$ was two orders of magnitude smaller than measured on guinea-pig papillary muscle preparations [67] or with rabbit Langendorff setups [68].

In view of the reciprocal action of veratridine and lidocaine on sodium channels, their identical negative chronotropic effects seem remarkable at first sight. Yet, the observed negative effect of veratridine on the heart rate is in accordance with findings in animal in vivo experiments [69].

\section{Can the CellDrum replace animal whole organ experiments?}

The answer is "yes", whenever a defined cell type and defined biomechanical/biophysical conditions or functional (mechanical) in near future high-throughput tests are necessary for direct comparisons of drug or experimental effects on cells. This avoids many organ specific, circulatory, metabolic and stress effects as present in whole organ studies. On the other hand whole organ studies cannot be replaced by the CellDrum whenever the whole organ matters e.g. in infarct size studies.

More detailed, the CellDrum is an idealized high precision experimental setup to test cultured cells for their ability to generate mechanical tension at various biochemical and -physical conditions. It enables precise measurements of this parameter using various (heart) cell types and at different conditions. It has the potential to simulate elevated blood pressure, oxygen partial pressure, and drug supply as well as to be upgraded to at least medium highthroughput testing. The CellDrum did never aim at heart infarct research studying effects of coronary blood flow nor at left ventricular pressure and infarct size in living explanted hearts. Circulating blood/energy supply in animal heart explants definitively changes contractile force but that is an issue far away from what the CellDrum aims at. However, at standardized conditions the CellDrum can simulate to certain extend conditions like ischemia/reperfusion by changing the oxygen partial pressure. As detailed in "methods" hiPS cells used here are a mixture of different heart cells. Future experiments may aim at separating those cells and perform individual cell type testing. In the adult heart especially for cardiomyocytes there is no typical cell division.

\section{Conclusions}

In summary, we conclude that the CellDrum technology is an accurate high precision method to quantify mechanical properties of cardiac myocyte cell layers in vitro. It combines 


\section{Cellular Physiology Cell Physiol Biochem 2016;38:1182-1198 \\ \begin{tabular}{l|l} 
and Biochemistry Published online: March 17, 2016 & $\begin{array}{l}\text { DOI: } 2016 \text { The Author(s). Published by S. Karger AG, Basel } \\
\text { www.karger.com/cpb }\end{array}$
\end{tabular} \\ Goßmann et al.: Mechano-Pharmacological Characterization of hiPS-CMs}

a high degree of handling simplicity and allows for precise conclusions on cellular mechanics. The major advantage of this approach is its potential scalability towards medium- and highthroughput-screening systems. The application of Laplace's law on circular tissue constructs enables biaxial measurement of cellular tensile stress. Hence, cellular alignment is not necessary for the acquisition of the exerted stress. As a result, this setup eliminates common deviations caused by improper control of the geometry of the specimen. As a research tool with well-defined biomechanical boundary conditions and its potential for upgrading the technology to high throughput tests the CellDrum satisfies many needs for drug testing of cardiomyocytes as well as the mechanical characterization of other cells and tissues. The experimental setup offers the possibility to simulate acute and chronic cardiovascular hypertension by adjustment of the membrane deflection through application of pneumatic pressure. Adopting the current 2D CellDrum technology to a 3D model may bring it closer to the three-dimensional environment in ventricular tissue. In addition, the CellDrum benefits from the fact that myocytes are not grown on a stiff substrate but on highly flexible membranes mimicking to some extend the natural compliance of soft tissue [70]. Yet, the highly anisotropic three dimensional environment and several other factors still rely on full organ tests suffering from the drawback of a non-scientific experimental setup - the heart of an animal. However, the parallel mathematical modeling and simulation allows in principle a transfer to different types of cardiac myocytes as well as to the anisotropic behavior of oriented tissues.

At present, human induced pluripotent stem cells promise to bring about a turning point affecting numerous applications from pharmacology to toxicology. Besides ethical advantages over animal models and the prevention of concerns regarding the translatability of the pharmacological results, hiPS-CMs can be produced in an infinite amount from individuals with known medical and clinical history. Yet, the promises of the new technology bear a certain number of unanswered questions to date. In particular, iPS-derived cardiac cells are suspected to not reflect the maturity of adult somatic cells, especially concerning the functionality of ion channel and expression of specific receptors [71,72]. As a result, stem cell-derived cardiomyocytes show deviations in their electrophysiological characteristics depending on the respective cell line [73]. Despite these issues, we have shown consistent and physiological responses of hiPS-derived cardiomyocytes on well-characterized inotropic compounds. Hence, the findings of this study support the hypothesis that iPS-derived cardiac myocytes can provide an adequate model for pharmacological and toxicological studies. New strategies for the differentiation of stem cells promise to improve the functional consistency of hiPS-derived cardiomyocytes $[74,75]$.

During stem cell proliferation and differentiation, oxygen levels play an important role for maintaining their potency and enabling or restricting differentiation, respectively. Tetramethylpyrazine was shown to anticipate hypoxia-induced myocardial cell apoptosis and hence might become an important tool during stem cell cultivation and differentiation [76].

Beyond improvements in the differentiation process, the maturation from embryonic to adult phenotype plays an emerging role. Recent findings disclose new putative drugs that might facilitate accelerated maturation in-vitro like puerarin, a compound found in traditional Chinese medicine [77]. Future studies with hiPS-derived electrocompetent cardiac fibroblasts and biomimetic three-dimensional connective tissue scaffolds may improve the physiological conditions towards a more concise cardiac tissue model. Sufficient supply with oxygen and nutrients remains the fundamental hurdle in three-dimensional tissue construction. One approach to overcome this obstacle could be the induction of selfvascularization of the tissue. Recently it was shown that placental growth factor plays an important role in this process in vivo [78].In respect to in vitro three-dimensional models of cardiomyocytes and cardiac firoblasts, the parallel mathematical modeling and numerical simulation may be further developed to understand and predict maturation of iPS-derived cells and predict the transfer to adult cells. 


\section{Cellular Physiology Cell Physiol Biochem 2016;38:1182-1198

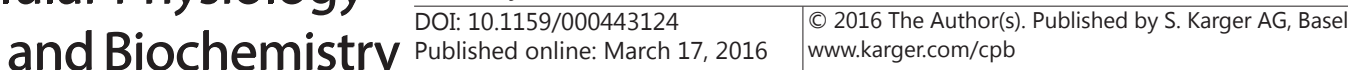 \\ Goßmann et al.: Mechano-Pharmacological Characterization of hiPS-CMs}

\section{Acknowledgements}

We gratefully thank Europe - Investment in our future. The project has been selected from the operational program for NRW in 'Ziel 2 Regionale Wettbewerbsfähigkeit und Beschäftigung' 2007-2013, which is co-financed by EFRE. The work was supported in addition by the State Ministry of Economic Affairs, Energy and Industry of North RhineWestphalia, Germany in the framework of the program "Transfer.NRW: FH-Extra" (FKZ: 0051009-0058). Thereafter the first two authors have been financed by a grant No. 1403ts021 obtained in "NRW Förderwettbewerb Stammzellforschung" of the Ministry of Innovation, Science and Research of the State of North Rhine-Westphalia. We thank Peter Öhlschläger and Edeltraut Ruttkowski for their consultancy and advice on biosafety and Dariusz Porst as well as Peter Kayser for technical and administrative support.

\section{Disclosure Statement}

The authors declare no competing interests.

\section{References}

1 Langendorff O: Untersuchungen am überlebenden Säugethierherzen. Pflügers Arch 1895;61:291-332.

2 Bell RM, Mocanu MM, Yellon DM: Retrograde heart perfusion: the Langendorff technique of isolated heart perfusion. J Mol Cell Cardiol 2011;50:940-950.

3 Shepherd N, Kavaler F: Direct control of contraction force of single frog atrial cells by extracellular ions. Am J Physiol Physiol 1986;251:653-661.

4 van der Velden J, Papp Z, Zaremba R, Boontje NM, de Jong JW, Owen VJ, Burton PBJ, Goldmann P, Jaquet $\mathrm{K}$, Stienen GJM: Increased $\mathrm{Ca}^{2+}$-sensitivity of the contractile apparatus in end-stage human heart failure results from altered phosphorylation of contractile proteins. Cardiovasc Res 2003;57:37-47.

5 Xi J, Khalil M, Shishechian N, Hannes T, Pfannkuche K, Liang H, Fatima A, Haustein M, Suhr F, Bloch W, Reppel M, Šarić T, Wernig M, Jänisch R, Brockmeier K, Hescheler J, Pillekamp F: Comparison of contractile behavior of native murine ventricular tissue and cardiomyocytes derived from embryonic or induced pluripotent stem cells. FASEB J 2010;24:2739-2751.

6 Harris A, Wild P, Stopak D: Silicone rubber substrata: a new wrinkle in the study of cell locomotion. Science 1980;208:177-179.

7 Hersch N, Wolters B, Dreissen G, Springer R, Kirchgeßner N, Merkel R, Hoffmann B: The constant beat: cardiomyocytes adapt their forces by equal contraction upon environmental stiffening. Biol Open 2013;2:351-361.

8 Yin S, Zhang X, Zhan C, Wu J, Xu J, Cheung J: Measuring single cardiac myocyte contractile force via moving a magnetic bead. Biophys J 2005;88:1489-1495.

9 Chicurel ME, Chen CS, Ingber DE: Cellular control lies in the balance of forces. Curr Opin Cell Biol 1998;10:232-239.

10 Galbraith C: Forces on adhesive contacts affect cell function. Curr Opin Cell Biol 1998;10:566-571.

11 Saenz Cogollo JF, Tedesco M, Martinoia S, Raiteri R: A new integrated system combining atomic force microscopy and micro-electrode array for measuring the mechanical properties of living cardiac myocytes. Biomed Microdevices 2011;13:613-621.

12 van Vliet KJ, Bao G, Suresh S: The biomechanics toolbox: experimental approaches for living cells and biomolecules. Acta Mater 2003;51:5881-5905.

13 Alford PW, Feinberg AW, Sheehy SP, Parker KK: Biohybrid thin films for measuring contractility in engineered cardiovascular muscle. Biomaterials 2010;31:3613-3621.

14 Agarwal A, Goss JA, Cho A, McCain ML, Parker KK: Microfluidic heart on a chip for higher throughput pharmacological studies. Lab Chip 2013;13:3599-3608. 


\section{Cellular Physiology Cell Physiol Biochem 2016;38:1182-1198

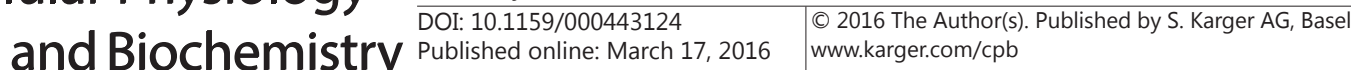 \\ Goßmann et al.: Mechano-Pharmacological Characterization of hiPS-CMs}

15 Shim J, Grosberg A, Nawroth JC, Parker KK, Bertoldi K: Modeling of cardiac muscle thin films: pre-stretch, passive and active behavior. J Biomech 2012;45:832-841.

16 McCain ML, Yuan H, Pasqualini FS, Campbell PH, Parker KK: Matrix elasticity regulates the optimal cardiac myocyte shape for contractility. Am J Physiol Heart Circ Physiol 2014;306:H1525-39.

17 Eschenhagen T, Fink C, Remmers U, Scholz H, Wattchow J, Weil J, Zimmermann W, Dohmen HH, Schäfer H, Bishopric N, Wakatsuki T, Elson EL: Three-dimensional reconstitution of embryonic cardiomyocytes in a collagen matrix: a new heart muscle model system. FASEB J 1997;11:683-694.

18 Zimmermann WH, Fink C, Kralisch D, Remmers U, Weil J, Eschenhagen T: Three-dimensional engineered heart tissue from neonatal rat cardiac myocytes. Biotechnol Bioeng 2000;68:106-114.

19 Hansen, A., Eder A, Bönstrup M, Flato M, Mewe M, Schaaf S, Aksehirlioglu B, Schwoerer AP, Uebeler J, Eschenhagen T: Development of a drug screening platform based on engineered heart tissue. Circ Res 2010;107:35-44.

20 Pillekamp F, Haustein M, Khalil M, Emmelheinz M, Nazzal R, Adelmann R, Nguemo F, Rubenchyk O, Pfannkuche K, Matzkies M, Reppel M, Bloch W, Brockmeier K, Hescheler J: Contractile properties of early human embryonic stem cell-derived cardiomyocytes: beta-adrenergic stimulation induces positive chronotropy and lusitropy but not inotropy. Stem Cells Dev 2012;21:2111-2121.

21 Lee P, Klos M, Bollensdorff C, Hou L, Ewart P, Kamp TJ, Zhang J, Bizy A, Guerrero-Serna G, Kohl P, Jalife J, Herron TJ: Simultaneous voltage and calcium mapping of genetically purified human induced pluripotent stem cell-derived cardiac myocyte monolayers. Circ Res 2012;110:1556-1563.

22 Sandow A: Excitation-contraction coupling in muscular response. Yale J Biol Med 1952;25:176-201.

23 Janssen PM, Datz N, Zeitz O, Hasenfuss G: Levosimendan improves diastolic and systolic function in failing human myocardium. Eur J Pharmacol 2000;404:191-199.

24 Teerlink JR: A novel approach to improve cardiac performance: cardiac myosin activators. Heart Fail Rev 2009;14:289-298.

25 Farman GP, Tachampa K, Mateja R, Cazorla O, Lacampagne A, de Tombe PP: Blebbistatin: use as inhibitor of muscle contraction. Pflügers Arch 2008;455:995-1005.

26 Giaever I, Keese C: Use of electric fields to monitor the dynamical aspect of cell behavior in tissue culture. IEEE Trans Biomed Eng 1986;33:242-247.

27 Wegener J, Keese CR, Giaever I: Electric cell-substrate impedance sensing (ECIS) as a noninvasive means to monitor the kinetics of cell spreading to artificial surfaces. Exp Cell Res 2000;59:158-166.

28 Xiao C, Luong JHT: On-line monitoring of cell growth and cytotoxicity using electric cell-substrate impedance sensing (ECIS). Biotechnol Prog 2003;19:1000-1005.

29 Trzewik J, Artmann-Temiz A, Linder PT, Demirci T, Digel I, Artmann GM: Evaluation of lateral mechanical tension in thin-film tissue constructs. Ann Biomed Eng 2004;32:1243-1251.

30 Trzewik J, Ates M, Artmann GM: A novel method to quantify mechanical tension in cell monolayers. Biomed Tech (Berl) 2002;47:S379-381.

31 Linder P, Trzewik J, Rüffer M, Artmann GM, Digel I, Rothermel A, Robitzki A, Temiz Artmann A: Contractile tension and beating rates of self-exciting monolayers and 3D-tissue constructs of neonatal rat cardiomyocytes. Med Biol Eng Comput 2010;48:59-65.

32 Demirci EK, Demirci T, Linder P, Trzewik J, Gierkowski JR, Gossmann M, Kayser P, Porst D, Digel I, Artmann GM, Artmann AT: RhAPC reduces the endothelial cell permeability via a decrease of contractile tensions induced by endothelial cells. J Biosci Bioeng 2012;114:212-219.

33 Artmann G: Device and method for the measurement of forces from living materials, Patents, Ref. No: US020040033482A1, 08/2000, AU000007638401A, 08/2000, EP000001311850B1, 08/2000, CA 2420141, 07/2002.

34 Trzewik J: Experimental analysis of biaxial mechanical tension in cell monolayers and cultured threedimensional tissues: the celldrum technology. PhD thesis, Technical University Ilmenau, 2008.

35 Trzewik J, Linder P, Zerlin K: Bioengineering in Cell and Tissue Research; in Artmann G, Chien S (eds): Bioengineering in Cell and Tissue Research Berlin, Heidelberg, Springer, 2008, pp 351-369.

36 Gross D, Hauger W, Schröder J, Wall WA, Bonet J: Engineering Mechanics 2. Mechanics of Materials, ed 1, Springer, Berlin Heidelberg, 2011.

37 Sui G, Wang J, Lee C-C, Lu W, Lee SP, Leyton JV, Wu AM, Tseng H-R: Solution-phase surface modification in intact poly(dimethylsiloxane) microfluidic channels. Anal Chem 2006;78:5543-5551. 


\section{Cellular Physiology Cell Physiol Biochem 2016;38:1182-1198

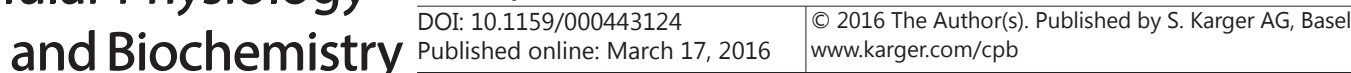 \\ Goßmann et al.: Mechano-Pharmacological Characterization of hiPS-CMs}

38 Witucki GL: A silane primer: chemistry and applications of alkoxy silanes. J Coatings Technol 1993;65:5760.

39 Zhou J, Ellis AV, Voelcker NH: Recent developments in PDMS surface modification for microfluidic devices. Electrophoresis 2010;31:2-16.

40 Takahashi K, Tanabe K, Ohnuki M, Narita M, Ichisaka T, Tomoda K, Yamanaka S: Induction of pluripotent stem cells from adult human fibroblasts by defined factors. Cell 2007;131:861-872.

41 Scheel O, Frech S, Amuzescu B, Eisfeld J, Lin K-H, Knott T: Action potential characterization of human induced pluripotent stem cell-derived cardiomyocytes using automated patch-clamp technology. Assay Drug Dev Technol 2014;12:457-469.

42 Frotscher R, Gossmann M, Temiz-Artmann A, Raatschen H-J, Staat M: Simulation of cardiac cell-seeded membranes using the edge-based smoothed FEM; in Altenbach H, Mikhasev GI (eds): Shell and Membrane Theories in Mechanics and Biology: From Macro- to Nanoscale Structures, Cham, Springer, 2015, pp. 187212.

43 Frotscher R, Koch J-P, Staat M: Computational investigation of drug action on human- induced stem cell derived cardiomyocytes. ASME. J Biomech Eng 2015;137:071002-071002-7.

44 Frotscher R, Muanghong D, Dursun G, Goßmann M, Temiz-Artmann A, Staat M: Sample-specific adaption of an improved computational model of cardiac tissue. J Biomechanics 2016; DOI: 10.1016/j. jbiomech.2016.01.039.

45 Shepherd N: Force measurements from voltage-clamped guinea pig ventricular myocytes. Am J Physiol Circ Physiol 1990;258:452-459.

46 Ryu S, Kim B, Kim D, Park S: Comparative quantification of contractile force of cardiac muscle using a micro-mechanical cell force measurement system. Conf. Proc. IEEE Eng Med Biol Soc 2005;5:5077-5080.

47 Papp Z, Szabo A, JBarends JP, Stienen GJM: The mechanism of the force enhancement by MgADP under simulated ischaemic conditions in rat cardiac myocytes. J Physiol 2002;543:177-189.

48 Verduyn SC, Zaremba R, van der Velden J, Stienen GJM: Effects of contractile protein phosphorylation on force development in permeabilized rat cardiac myocytes. Basic Res Cardiol 2007;102:476-487.

49 Zimmermann WH, Didié M, Wasmeier GH, Nixdorff U, Hess A, Melnychenko I, Boy O, Neuhuber WL, Weyand M, Eschenhagen T: Cardiac grafting of engineered heart tissue in syngenic rats. Circulation 2002;106:I-151-I-157.

50 Grosberg A, Alford PW, McCain ML, Parker KK: Ensembles of engineered cardiac tissues for physiological and pharmacological study: Heart on a chip. Lab Chip 2011;11:4165-4173.

51 van der Velden J, Klein LJ, van der Bijl M, Huybregts MA, Stooker W, Witkop J, Eijsman L, Visser CA, Visser FC, Stienen GJ: Force production in mechanically isolated cardiac myocytes from human ventricular muscle tissue. Cardiovasc Res 1998;38:414-423.

52 Thomas G, Chung M, Cohen CJ: A dihydropyridine (Bay k 8644) that enhances calcium currents in guinea pig and calf myocardial cells. A new type of positive inotropic agent. Circ Res 1985;56:87-96.

53 Greenstein JL, Hinch R, Winslow RL: Mechanisms of excitation-contraction coupling in an integrative model of the cardiac ventricular myocyte. Biophys J 2006;90:77-91.

54 Finet M, Godfraind T, Khoury G: The positive inotropic action of the nifedipine analogue, Bay K 8644, in guinea-pig and rat isolated cardiac preparations. Br J Pharmacol 1985;86:27-32.

55 Dubé GP, Baik YH, Schwartz A: Effects of a novel calcium channel agonist dihydropyridine analogue, Bay $\mathrm{k}$ 8644, on pig coronary artery: biphasic mechanical response and paradoxical potentiation of contraction by diltiazem and nimodipine. J Cardiovasc Pharmacol 1985;7:377-389.

56 Kates RA, Zaggy AP, Norfleet EA, Heath KR: Comparative cardiovascular effects of verapamil, nifedipine, and diltiazem during halothane anesthesia in swine. Anesthesiology 1984;61:10-18.

57 Katz AM, Hager WD, Messineo FC, Pappano AJ: Cellular actions and pharmacology of the calcium channel blocking drugs. Am J Med 1984;77:2-10.

58 Singh BN, Vaughan Williams EM: A fourth class of anti-dysrhythmic action? Effect of verapamil on ouabain toxicity, on atrial and ventricular intracellular potentials, and on other features of cardiac function. Cardiovasc Res 1972;6:109-119.

59 Harada S, Sada H, Kojima M, Ban T: Negative inotropic effects of tiapamil (Ro11-1781) and verapamil in rabbit myocardium. Eur J Pharmacol 1982;78:7-14. 


\section{Cellular Physiology Cell Physiol Biochem 2016;38:1182-1198

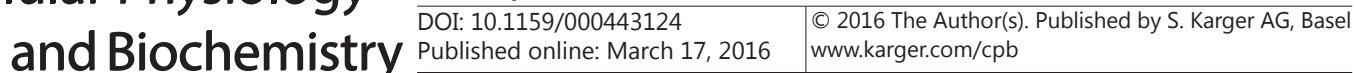 \\ Goßmann et al.: Mechano-Pharmacological Characterization of hiPS-CMs}

60 Bayer R, Hennekes R, Kaufmann R, Mannhold R: Inotropic and electrophysiological actions of verapamil and D600 in mammalian myocardium - I. Pattern of inotropic effects of the racemic compounds. NaunynSchmiedeberg's Arch Pharmacol 1975;290:49-68.

61 Nayler WG, Szeto J, Berry D: Effect of verapamil on contractility, oxygen utilization, and calcium exchangeability in mammalian heart muscle. Cardiovasc Res 1972;6:120-128.

62 Ji J, Kang J, Rampe D: L-type $\mathrm{Ca}^{2+}$ channel responses to Bay K 8644 in stem cell-derived cardiomyocytes are unusually dependent on holding potential and charge carrier. Assay Drug Dev Technol 2014;12:352-360.

63 Kane C, Couch L, Terracciano CMN: Excitation-contraction coupling of human induced pluripotent stem cell-derived cardiomyocytes. Front Cell Dev Biol 2015;3:59.

64 Hashimoto K, Tsukada T, Matsuda H: Inotropic and chronotropic effects of antiarrhythmic agents on isolated blood-perfused canine ventricular tissue. Recent Adv Stud Cardiac Struct Metab 1976;11:451-455.

65 Satoh H: Comparison of the chronotropic responses to local anesthetics (procaine, lidocaine, prilocaine, mepivacaine and bupivacaine) of the canine sinus node in situ. Jpn J. Pharmacol 1981;31:85-93.

66 Honerjäger P, Reiter M: The relation between the effects of veratridine on action potential and contraction in mammalian ventricular myocardium. Naunyn-Schmiedeberg's Arch Pharmacol 1975;289:1-28.

67 Lynch C: Depression of myocardial contractility in vitro by bupivacaine, etidocaine, and lidocaine. Anesth Analg 1986;65:551-559.

68 Clarkson CW, Follmer CH, ten Eick RE, Hondeghem LM, Yeh JZ: Evidence for two components of sodium channel block by lidocaine in isolated cardiac myocytes. Circ Res 1988;63:869-878.

69 Barron K, Bishop V: Reflex cardiovascular changes with veratridine in the conscious dog. Am J Physiol 1982;242:H810-H817.

70 Heras-Bautista C, Katsen-Globa A, Schloerer N, Dieluweit S, Abd El Aziz O, Peinkofer G, Attia W, Khalil M, Brockmeier K, Hescheler J, Pfannkuche K: The influence of physiological matrix conditions on permanent culture of induced pluripotent stem cell-derived cardiomyocytes. Biomaterials 2014;35:7374-7385.

71 Scott CW, Peters MF, Dragan YP: Human induced pluripotent stem cells and their use in drug discovery for toxicity testing. Toxicol Lett 2013;219:49-58.

72 Sheehy SP, Pasqualini F, Grosberg A, Park SJ, Aratyn-Schaus Y, Parker KK: Quality metrics for stem cellderived cardiac myocytes. Stem Cell Reports 2014;2:282-294.

73 Hannes T, Wolff M, Doss MX, Pfannkuche K, Haustein M, Müller-Ehmsen J, Sachinidis A, Hescheler J, Khalil M, Halbach M: Electrophysiological characteristics of embryonic stem cell-derived cardiomyocytes are cell line-dependent. Cell Physiol Biochem 2015;35;305-314.

74 Xu R, Srinivasan SP, Sureshkumar P, Nembo EN, Schäfer C, Semmler J, Matzkies M, Albrechtsen M, Hescheler J, Nguemo F: Effects of synthetic neural adhesion molecule mimetic peptides and related proteins on the cardiomyogenic differentiation of mouse embryonic stem cells. Cell Physiol Biochem 2015;35:2437-2450.

75 Ivanyuk D, Budash G, Zheng Y, Gaspar JA, Chaudhari U, Fatima A, Bahmanpour S, Grin VK, Popandopulo AG, Sachinidis A, Hescheler J, Šaric T: Ascorbic acid-induced cardiac differentiation of murine pluripotent stem cells: transcriptional profiling and effect of a small molecule synergist of Wnt/ $\beta$-catenin signaling pathway. Cell Physiol Biochem 2015;36:810-830.

76 Lin KH, Kuo WW, Jiang AZ, Pai P, Lin JY, Chen WK, Day CH, Shen CY, Padma VV, Huang CY: Tetramethylpyrazine ameliorated hypoxia-induced myocardial cell apoptosis via HIF-1 $\alpha / \mathrm{JNK} / \mathrm{p} 38$ and IGFBP3/BNIP3 inhibition to upregulate PI3K/Akt survival signaling. Cell Physiol Biochem 2015;36:334344.

77 Wang L, Cui Y, Tang M, Hu X, Luo H, Hescheler J, Xi J: Puerarin facilitates T-tubule development of murine embryonic stem cell-derived cardiomyocytes. Cell Physiol Biochem 2014;34:383-392.

78 Zhang J, Wu Y, Chen A, Zhao Q: Mesenchymal stem cells promote cardiac muscle repair via enhanced neovascularization. Cell Physiol Biochem 2015;35:1219-1229. 